\title{
Assessment of Knowledge and Practices of Diabetic Patients Regarding Diabetic Foot Care, in Makkah, Saudi Arabia
}

\author{
Reda Goweda ${ }^{1}$, Mokhtar Shatla ${ }^{2}$, Arwa Alzaidi ${ }^{3}$, Arij Alzaidi ${ }^{4}$, Bashaer Aldhawani ${ }^{3}$, \\ Hibah Alharbi ${ }^{4}$, Noran Sultan ${ }^{4}$, Daniah Alnemari ${ }^{4}$, Badr Rawa ${ }^{5}$ \\ ${ }^{1}$ Department of Family Medicine, Faculty of Medicine, Suez Canal University, Ismailia, Egypt \\ ${ }^{2}$ Department of Family Medicine, Faculty of Medicine, Menoufia University, Menoufia, Egypt \\ ${ }^{3}$ Ministry of Health, Makkah, Saudi Arabia \\ ${ }^{4}$ Faculty of Medicine, Umm Alqura University, Makkah, Saudi Arabia \\ ${ }^{5}$ Faculty of Medicine, Ibn Sinai National College, Jeddah, Saudi Arabia
}

Email address:

mokhtarshatla@gmail.com (M. Shatla)

\section{To cite this article:}

Reda Goweda, Mokhtar Shatla, Arwa Alzaidi, Arij Alzaidi, Bashaer Aldhawani, Hibah Alharbi, Noran Sultan, Daniah Alnemari, Badr Rawa. Assessment of Knowledge and Practices of Diabetic Patients Regarding Diabetic Foot Care, in Makkah, Saudi Arabia. Journal of Family Medicine and Health Care. Vol. 3, No. 1, 2017, pp. 17-22. doi: 10.11648/j.jfmhc.20170301.14

Received: June 26, 2016; Accepted: July 8, 2016; Published: February 18, 2017

\begin{abstract}
Background: $20.5 \%$ of Saudis between 20 and 79 years are diabetics. Diabetic foot is a chronic complication of diabetes. The incidence of non-traumatic lower extremity amputations is at least 15 times greater in those with diabetes than non-diabetics. Patient education is important to reduce lower extremity complications. Objective: To assess the knowledge and practices of the diabetic patients regarding foot care and diabetic foot complications. Methods: In Makkah hospitals, 350 diabetic patients who met the inclusion criteria were involved in this cross sectional study. Interviewing questionnaire and patients' charts review were used to collect the data. Results: Mean age of patients was $53.0083 \pm 13.1$ years, and mean duration of diabetes was $11.24 \pm 8.7$ years. $35.1 \%$ had history of foot ulcer while $25.7 \%$ had ulcer on the time of interview. $11.7 \%$ had history of amputation and $83.1 \%$ had numbness. $77.1 \%$ examine their feet while $49.1 \%$ received foot care education and $34 \%$ read handouts on foot care. 34\% walk around in bare feet. There is a significant statistical association between foot education, practices and diabetic foot ulcer ( $\mathrm{p}$-value $<0.05$ ). Conclusion: Patient knowledge and practices regarding diabetic foot care is significantly associated with the reduction of diabetic foot ulcer.
\end{abstract}

Keywords: Knowledge, Practice, Diabetes, Foot Care

\section{Introduction}

Diabetes mellitus (DM) is a major public health problem that is increasing in its prevalence. The number of people affected by DM was expected to rise from 171 million in the year 2000 to 366 million by 2030. [1] In 2011, there were 366 million people affected with diabetes mellitus globally. [2] In 2014, The International Diabetes Federation estimated that there were $20.5 \%$ of Saudis between 20 and 79 years are diabetics. [3]

Together with the rising prevalence of diabetes, a substantial increase in its complications is expected. [4] One of the most serious complications of diabetes causing high degrees of morbidities and mortalities and care cost is diabetic foot. It describes various degrees of angiopathy and neuropathy affecting the foot with tendency towards destruction of the foot tissue, ulceration and infection. ${ }^{[5]}$ Many risk factors may lead to diabetic foot including long duration of diabetes, poor metabolic control, foot deformities, older age, peripheral vasculo-pathy and poor knowledge of diabetics. [5]

Diabetic foot was found to affect $8-17 \%$ of diabetics. [6] 
Almost $85 \%$ of diabetes-related amputations are preceded by foot ulcers, and it accounts for more than $50 \%$ of non-traumatic lower limb amputations, [7] which is at least 15 times greater in those with diabetes than non-diabetics. American Diabetes Association estimates that one in five people with diabetes who seek hospital care do so for foot problems. [4]

Of all the diabetes related complications, those that occur in the foot are considered the most preventable. [8, 9] The United Kingdom Prospective Diabetes Study has shown that appropriate control of blood sugar through dietary control, exercise and proper medications prevents the development of microvascular complications. [6] Apparently, the practice of diabetic foot care measures such as daily foot examination and the use of appropriate footwear are important as regard the early detection and prevention of the expected complications. Patients with poor knowledge and practices regarding diabetic foot care have a higher incidence of foot complications including ulcers. [10] Studies suggest that patient education with proper foot care practices may reduce diabetes related foot ulceration and amputations. [11] Also, foot care practices reduce common foot problems such as corns and callosities and facilitate healing of foot ulcers.[12]

There have been few studies on knowledge and practices regarding foot care among diabetic patients in Saudi Arabia, but studies like these are crucial for prevention of drastic foot complications like foot ulcers and amputation. The objectives of the current study was to assess the patients' knowledge and practices regarding self-foot care among diabetic patients attending secondary care hospitals in Makkah, Saudi Arabia. The information gained on the knowledge and practices regarding foot care can aid health care providers and policy makers to develop targeted self-management education programs for people with diabetes.

\section{Methods}

This was a cross sectional study conducted at the outpatient clinics of three secondary healthcare hospitals (Alzahir, Security Forces, and Al-Nour), in Makkah, Saudi Arabia during the first quarter of 2015. Ethical approval was obtained from the ethics and research review committee of Umm Alqurah Faculty of Medicine.

A total of 350 diabetic patients were surveyed in consideration of the inclusion and exclusion criteria where adult diabetic patients above the age of 18 who consented to participate in the study were included. Simple random selection of patients who met the inclusion criteria was surveyed.

A method that has been used in various studies in different countries [13, 14] was adapted for this study of knowledge and self-foot-care practices in a Saudi population. The knowledge and self-foot care practices of the subjects were assessed via a structured, pre-tested and an intervieweradministered questionnaire. The interview was hold in the outpatient department (OPD) setting of the mentioned hospitals. The questionnaire was administered by MBBS students who were adequately trained to ensure uniform data collection in the Arabic language.

\subsection{Study Instrument}

A medium-sized-four-parts questionnaire adopted from the Diabetic Foot Care Questionnaire of Diabetes Care Program Nova Scotia 2009 was used for data collection [15]. The first part of the questionnaire consisted of sociodemographic and some clinical information; the body mass index (BMI) and the level of the patient's glycated hemoglobin $(\mathrm{HgAl})$. The second part explores the history of foot problems involving 3 questions about the past history, and 5 questions about the current history of foot problems. The third part consisted of 18 questions about foot care practices divided into 6 questions about basic foot care practices, 2 questions about the kind of foot wear, and 10 questions about practices for safety and prevention of foot problems. The fourth part focused on foot care education and consisting of 4 questions.

A pilot study on 30 patients was done prior to the start of the study to ensure reliability of the questionnaire and to ensure the questions asked were understood by the respondents.

Patients' charts were reviewed to collect data regarding $\mathrm{BMI}$ and $\mathrm{HbA1c}$.

\subsection{Statistical Analysis}

The results were collected, tabulated and statistically analyzed by SPSS software program (Statistical Program for Social Science), Version 20. Quantitative data were expressed as mean and standard deviation. Qualitative data were expressed as numbers and percentages. To assess the differences in frequencies on the dichotomized qualitative variables (scored present or absent) Chi-Square test $\left(\chi^{2}\right)$ was used with $5 \%$ level of significance.

\section{Results}

Mean age of patients was $53 \pm 13.1$ years, and mean duration of diabetes was $11.24 \pm 8.7$ years. Among the diabetes patients $160(45.7 \%)$ are males and $190(54.3 \%)$ are females. Majority of the patient's education $136(36.9 \%)$ belong to low education (primary school and read and write) with no illiterate patients, $103(29.4 \%)$ belong to moderate education who had secondary school, $118(33.7 \%)$ belong to high education who had university and postgraduate education. Majority of the patients 183 (80.9\%) were Saudi, 300 (85.7) were married, 2 (4\%).106 (30.3) were smokers. Maximum number of patients 179 $(51.1 \%)$ were having duration of diabetes more than $10 \mathrm{yrs}$ $35.1 \%$ had history of foot ulcer while $25.7 \%$ had ulcer on the time of interview. $11.7 \%$ had history of amputation and $83.1 \%$ had numbness. $77.1 \%$ examine their feet while $49.1 \%$ received foot care education and 34\% read handouts on foot care. $34 \%$ walk around in bare feet. There is a significant statistical association between foot education, foot care practices, and diabetic foot ulcer ( $\mathrm{p}$-value $<0.05$ ) 
Table 1. Socio-demographic Characteristics of Patients.

\begin{tabular}{lll}
\hline Patient Characteristics & \multicolumn{2}{l}{ Total number of patients (350) } \\
\cline { 2 - 3 } Number & Percentage (\%) \\
\hline Gender & & \\
- Male & 160 & 45.7 \\
Nationality & 190 & 54.3 \\
- Saudi & & \\
- Non Saudi & 283 & 80.9 \\
Marital status & 67 & 19.1 \\
- Married & & \\
- Single & 300 & 85.7 \\
- Divorced & 31 & 8.9 \\
Education & 19 & 5.4 \\
- High & & \\
- Moderate & 118 & 33.7 \\
- Low education & 103 & 29.4 \\
Duration of DM & 129 & 36.9 \\
- <1 year & & \\
- 1-5 & 16 & 4.6 \\
- 6-10 & 85 & 24.3 \\
- >10 & 70 & 20.0 \\
BMI & 179 & 51.1 \\
- Overweight & 126 & 36.0 \\
- Obese & 175 & 50 \\
HbA1c & & \\
- Controlled & 47 & \\
\hline
\end{tabular}

Table 2. Past and current history of foot problem.

\begin{tabular}{lll}
\hline \multirow{2}{*}{ Type of foot problem } & \multicolumn{2}{c}{ Total number of patients (350) } \\
\cline { 2 - 3 } & Number & Percentage (\%) \\
\hline Past history: & & \\
- Sore or cut on foot or leg & 138 & 39.4 \\
- Foot ulcer & 123 & 35.1 \\
- Amputation & 41 & 11.7 \\
Current history: & & \\
- Ulcer & 90 & 25.7 \\
- Blood on socks & 62 & 17.7 \\
- Calluses & 136 & 38.9 \\
- Numbness & 291 & 83.1 \\
- Tightness & 256 & 73.1 \\
\hline
\end{tabular}

Table 3. Foot care practices.

\begin{tabular}{lll}
\hline \multirow{2}{*}{ Type of foot problem } & \multicolumn{2}{l}{ Total number of patients (350) } \\
\cline { 2 - 3 } & Number & Percentage (\%) \\
\hline Examine feet daily & 269 & 76.9 \\
Frequency of examination & & \\
• every day & 132 & 37.7 \\
- 2-6 times week & 51 & 14.6 \\
• once per week or less & 30 & 8.6 \\
• only when has problem & 57 & 16.3 \\
Reach bottom of foot & 270 & 77.1 \\
wash feet everyday & 337 & 96.3 \\
dry well between the toes & 137 & 39.1 \\
use a moisturizing cream on feet & 218 & 62.3 \\
cut own toenails & 262 & 74.9 \\
Suitable shoes & 137 & 39.1 \\
Suitable socks & 215 & 61.5 \\
\hline
\end{tabular}

Table 4. Practices to prevent foot problems.

\begin{tabular}{lll}
\hline \multirow{2}{*}{ Practice } & \multicolumn{2}{l}{ Total number of patients (350) } \\
\cline { 2 - 3 } & Number & Percentage (\%) \\
\hline Soak feet & 109 & 31.1 \\
Test water temperature before & 170 & 48.6 \\
immersion & & \\
\hline
\end{tabular}

\begin{tabular}{lll}
\hline \multirow{2}{*}{ Practice } & \multicolumn{2}{c}{ Total number of patients (350) } \\
\cline { 2 - 3 } & Number & Percentage (\%) \\
\hline $\begin{array}{l}\text { Use medicated products for warts, } \\
\text { corns or calluses }\end{array}$ & 105 & 30.0 \\
$\begin{array}{l}\text { Put moisturizing creams or lotions } \\
\text { between toes }\end{array}$ & 118 & 33.7 \\
$\begin{array}{l}\text { Walk around in bare feet } \\
\text { Wear shoes without wearing any }\end{array}$ & 119 & 34.0 \\
$\begin{array}{l}\text { socks } \\
\text { Inspect shoes for foreign objects or }\end{array}$ & 185 & 52.9 \\
torn linings & 225 & \\
$\begin{array}{l}\text { Use a hot water bottle or heating pad } \\
\text { on feet }\end{array}$ & 63 & 64.3 \\
$\begin{array}{l}\text { Sit with legs crossed } \\
\text { Smoking }\end{array}$ & 141 & 18.0 \\
\hline
\end{tabular}

Table 5. Health education methods.

\begin{tabular}{|c|c|c|}
\hline \multirow{2}{*}{ Education Method } & \multicolumn{2}{|c|}{ Total number of patients (350) } \\
\hline & Number & Percentage (\%) \\
\hline $\begin{array}{l}\text { - Attended a class on how to care } \\
\text { for your feet }\end{array}$ & 172 & 49.1 \\
\hline - Read any handouts on foot care & 119 & 34.0 \\
\hline $\begin{array}{l}\text { - Read any handouts on proper } \\
\text { footwear }\end{array}$ & 102 & 29.1 \\
\hline $\begin{array}{l}\text { - Would like to have health } \\
\text { education }\end{array}$ & 291 & 83.1 \\
\hline
\end{tabular}

Table 6. Relationship between health education and foot care practices.

\begin{tabular}{|c|c|c|c|c|c|}
\hline & \multirow[b]{2}{*}{ Yes } & \multicolumn{2}{|c|}{$\begin{array}{l}\text { Attending classes for foot } \\
\text { education }\end{array}$} & \multirow{3}{*}{$\begin{array}{l}\mathbf{X}^{2} \\
2.977\end{array}$} & \multirow{2}{*}{$\begin{array}{l}\text { P value } \\
0.084\end{array}$} \\
\hline - Examine & & $139(80.8 \%)$ & $130(75.6 \%)$ & & \\
\hline feet & No & $33(19.2 \%)$ & $42(24.4 \%)$ & & 0.084 \\
\hline \multirow{2}{*}{$\begin{array}{l}\text { Use } \\
\text { moisturizing } \\
\text { creams }\end{array}$} & Yes & $119(69.2 \%)$ & $99(57.6 \%)$ & \multirow[b]{2}{*}{6.855} & \multirow[b]{2}{*}{0.009} \\
\hline & No & $53(30.8 \%)$ & $73(42.4 \%)$ & & \\
\hline \multirow{2}{*}{ - Soak feet } & Yes & $45(26.2 \%)$ & $64(37.2 \%)$ & \multirow{2}{*}{3.911} & \multirow{2}{*}{0.048} \\
\hline & No & $127(73.8 \%)$ & $108(62.8 \%)$ & & \\
\hline
\end{tabular}

Table 7. Relationship between health education and foot ulcer.

\begin{tabular}{llllll}
\hline & & \multicolumn{2}{l}{$\begin{array}{l}\text { Attending classes for foot } \\
\text { education }\end{array}$} & \multirow{2}{*}{$\mathbf{X}^{\mathbf{2}}$} & P value \\
\hline \multirow{3}{*}{ Foot ulcer } & Yes & $\begin{array}{l}\text { Yes } \\
\text { Yes }(29.7 \%)\end{array}$ & $\begin{array}{l}\text { No } \\
72(41.8 \%)\end{array}$ & 4.475 & 0.034 \\
& No & $121(72.3)$ & $100(58.2 \%)$ & & \\
\hline
\end{tabular}

\section{Discussion}

This study was conducted to assess the knowledge and practices of the diabetic patients on foot care. It was found that mean age of patients was $53.0083 \pm 13.1$ years, mean duration of diabetes was $11.24 \pm 8.7$ years, mean BMI was $30.58 \pm 6.24$ and mean $\mathrm{HgAl}$ c was $10.05 \pm 5.70$

The study showed feet numbness was complained by $83 \%$ of patients. Good blood sugar control was achieved in only $13.4 \%$ of patients, while poor control was observed in most of the patients (86.6\%). Similar findings were reported by Ali et al. who found that $54.2 \%$ of diabetic patients suffered from hotness sensation in their feet, feet numbness was complained by $47.7 \%$ of patients, and controlled blood glucose was achieved only by $14.1 \%$ of patients. [16] Similar finding was observed also by Al-Maskari and El-Sadig who conducted their cross-sectional survey to assess the 
prevalence of diabetes complications in Al-Ain district, United Arab Emirates. They reported symptoms including cramp like-pain in legs or feet, tingling, numbness, and burning sensations with a "stocking and glove distribution" in $35 \%$ of them, while good diabetes control was achieved by $38 \%$ of patients. [17]

Past and current history of foot problem of diabetic patients' feet within the present study revealed that $11.7 \%$ of patients underwent amputations as well as sores (39.4\%), skin ulcers $(35.1 \%)$, callus $(38.9 \%)$. This is higher than results of study of Ali et al. which revealed that amputation was detected in $1.4 \%$ of the patients, nails abnormalities (12.7\%), feet swelling (6.9\%), deformity (7.4\%), muscle atrophy $(6 \%)$, skin cracks/ulcers $(10.2 \%)$, callus $(6.9 \%)$, temperature fluctuation $(1.4 \%)$. This difference is explained by the fact that the most of the participants of the current study were hired from diabetic foot clinics providing specific and intensive care to patients with past or current history of diabetic foot problems.

The prevalence of diabetic foot in the present study is higher than that stated by Boulton, [18] who reported that, worldwide, the prevalence of the diabetic foot ranges between $1.4 \%$ and $5.9 \%$. He added that foot ulceration and amputation are significantly inter-related in diabetes. More than $85 \%$ of amputations resulted from a previous ulcer. Importantly, diabetes is the foremost cause of non-traumatic lower extremity amputation in the western world, amputation rates among diabetic patients being 15 times higher than in the non-diabetic subjects.

On analysis of foot care practices, the majority (76.9\%) of study subjects said they inspected their feet and $37.7 \%$ of them examine feet daily, while almost all (96.3\%) of the study subjects wash their feet regularly. This finding is different from the study carried out in Chandigarh, where it was found that only $63.3 \%$ of the patients with diabetes take care of their feet through regular washing. [19] This difference may be explained on the basis of the Islamic rituals which the participants of the current study are performing religiously without knowing that some of these activities are part of good foot care practices, so the participants were practicing washing of the feet as they did ablution before offering prayers. However, many other studies from India revealed poor foot care practices. [20]

In the current study, $64.3 \%$ of the respondents admitted they had the knowledge to always check the shoes before wearing. This coincides with the study done by Seema Hasnain et al. [21] that found $73.3 \%$ checked their shoes before wearing.

There were some deficiencies in the knowledge and practices regarding foot care identified by the current study. Many patients $(60.9 \%)$ don't dry their feet after washing, and $34.0 \%$ walk bare feted at home which is less than subjects in another study which revealed that vast majority $(87.3 \%)$ of patients walk bare feted. [22]

The prevalence of peripheral neuropathy in the current study was $81.1 \%$. The prevalence of peripheral neuropathy varied from $15 \%$ to $60 \%$ in different studies done in India.
[23] The variations could be because of the variations in the instruments used to detect peripheral neuropathy. The current study used one question regarding numbness, while in other studies the Mittchigan Neuropathy Screening Instrument (MNSI) was used to assess neuropathy. MNSI is a rapid, simple and reliable test for screening diabetic peripheral neuropathy in both diabetes clinics and epidemiological surveys. [24]

The role of physicians is very important in improving knowledge and practices regarding foot care and foot care education is the most crucial tool for preventing lower leg amputation. In this study $49.1 \%$ received information about diabetes through attending classes in diabetic foot care education, while $34 \%$ read handouts regarding foot care. In a study from Italy, more than $50 \%$ of the patients reported that they did not have their feet examined by their physician and $28 \%$ referred that they had not received foot education. Thus patients' knowledge and practices are strongly related to physicians' attitudes. [25]

The current study showed that educational brochures on foot self-care were received by about $34 \%$, while $49.1 \%$ attended classes for foot care health education. This is nearly in agreement with study by Ali et al. [16] who found that less than half of diabetic patients underwent feet examination by primary health care physicians. Health education sessions on importance of and how to conduct foot care have been held only for less than half of patients.

Al-Mahroos and Al-Roomi [26] emphasized that family physicians have a leading role in ensuring that patients with diabetes should receive early and optimal care and health education to prevent skin ulcers. However, foot examinations are infrequently performed by primary care physicians on diabetic patients and the feet of hospitalized diabetics are also inadequately evaluated.

In the current study, there was a significant statistical association between foot education, foot care practices, and diabetic foot ulcer ( $p$-value $<0.05$ ). Karter et al. [27] emphasized that the associations between educational attainment and health behaviors are particularly important in diabetes, given the critical role of health behaviors, including diabetes self-management and health-related life-style. Using a sample of managed care patients with diabetes, Karter et al. identified the relationships between educational attainment and smoking, physical activity, self-monitoring of blood glucose, foot self-exam, and diabetes-related health-seeking behaviors. In addition, Shah et al. [28] added that there is an increasing amount of evidence that the patient education is the most effective way to lessen the complications of diabetes and its management.

\section{Conclusion}

This study concludes a high rate of diabetic foot ulcers, incorrect knowledge, and improper practices. Patient education regarding diabetic foot care is associated with reduced foot ulcers. 


\section{Recommendations}

This study recommends improving diabetic patients' knowledge regarding foot care. This could be done through diabetic foot care clinics that should be readily available in every health care facility providing care to diabetic patients. The clinic should provide a diversity of health education methods using both classes and handouts to improve patients' knowledge and practices regarding foot care. Mass media utilized to transfer the health education message on the necessity of proper self-foot care.

\section{References}

[1] Wild S, Roglic G, Green A, Sicree R, King H: Global prevalence of diabetes: estimates for the year 2000 and projections for 2030 .

[2] Unwin N, Whiting D, Guariguata L, Ghyoot G, Gan D, editors. Diabetes Atlas. $5^{\text {th }}$ ed. Brussels, Belgium: International Diabetes Federation; 2011.

[3] International Federation of Diabetes Middle East and North Africa (2014): Available at http: //www.idf.org/membership/mena/saudi-arabia. Accessed March 20, 2015.

[4] American Diabetes Association. Economic costs of diabetes in the U.S. in 2012. Diabetes Care 2013; 36: 1033-46.

[5] Al-Wahbi AM. The diabetic foot in the Arab World. Saudi Medical Journal. 2006; 27 (2): 147-53

[6] Intensive blood-glucose control with sulphonylureas or insulin compared with conventional treatment and risk of complications in patients with type 2 diabetes (UKPDS 33). The Lancet 1998; 352: 837-53.

[7] Dang CN, Boulton AJ. Changing perspectives in diabetic foot ulcer management. Int J Low Extrem Wounds 2003; 2: $4-12$.

[8] The diabetic foot. Position statement. International Diabetes Federation [Internet]. Available from: http: //www. idf.org/position- statement-diabetic-foot. [Last cited on 2014 May 2].

[9] Chandalia HB, Singh D, Kapoor V, Chandalia SH, Lamba PS. Footwear and foot care knowledge as risk factors for foot problems in Indian diabetics. Int J Diabetes Dev Ctries 2008; 28: 109-13.

[10] Chellan G, Srikumar S, Varma AK, Mangalanandan TS, Sundaram KR, Jayakumar RV, et al. Foot care practice-the key to prevent diabetic foot ulcers in India. Foot (Edinb) 2012; 22: 298-302.

[11] Calle-Pascual AL, Durán A, Benedı A, Calvo MI, Charro A, Diaz JA, et al. A preventative foot care programme for people with diabetes with different stages of neuropathy. Diabetes Res Clin Pract 2002; 57: 111-7.

[12] Viswanathan V, Madhavan S, Rajasekar S, Chamukuttan S, Ambady R. Amputation prevention initiative in South India: Positive impact of foot care education. Diabetes Care 2005; 28: 1019-21.
[13] Mehrotra R, Bajaj S, Kumar D: Influence of education and occupation on knowledge about diabetes control. Natl Med J India 2000, 13: 293-296.

[14] Nicolucci A, Ciccarone E, Consoli A, Martino GD, Penna GL, Lattore A, et al.: Relationship between patient practiceoriented knowledge and metabolic control in intensively related type 1 diabetic patients: results of the validation of the knowledge and practices diabetes questionnaire. Diab Nutr Metab 2000, 13: 276-283.

[15] Diabetes care program Nova Scotia Annual Report 2009. Available at Website: www.diabetescareprogram.ns.ca. Accessed December 2014.

[16] Ali S. Al-asmary, Osama A. Mostafa, and Yahia M. Alkhaldi. Diabetic Patients' Knowledge and Practice Regarding Prevention of Diabetic Foot. Med. J. Cairo Univ., Vol. 81, No. 2, March: 197-205, 2013.

[17] Al-maskari F. and EL-SADIG M.: Prevalence of risk factors for diabetic foot complications. BMC Family Practice, 8: 59, 2007.

[18] Boulton AJM: The diabetic foot: Grand overview, epidemiology and pathogenesis. Diabetes. Metab. Res. Rev., 24 (Suppl 1): S3-S6, 2008.

[19] Kaur K, Singh MM, Kumar, Walia I. Knowledge and selfcare practices of diabetics in a resettlement colony of Chandigarh. Indian J Med Sci. 1998; 52: 341-7.

[20] Jayaprakash P, Bhansali S, Bhansali A, Dutta P, Anantharaman R. Magnitude of foot problems in diabetes in the developing world: A study of 1044 patients. Diabet Med. 2009; 26: 939-42.

[21] Seema Hasnain, Naheed Humayun Sheikh (Department of Community Medicine, Allama Iqbal Medical College, Lahore: Knowledge and practices regarding foot care in diabetic patients visiting diabetic clinic in Jinnah Hospital, Lahore. Journal of Pakistan Medical Association. 2009; 59 (10):687-90.

[22] Hanu George, Rakesh PS, Manjunath Krishna, Reginald Alex, Vinod Joseph Abraham, Kuryan George, and Jasmin H. Prasad. Foot care knowledge and practices and the prevalence of peripheral neuropathy among people with diabetes attending a secondary care rural hospital in southern India). J Family Med Prim Care. 2013 Jan-Mar; 2 (1): $27-$ 32.

[23] Nafisa CV, Ferreira AM, Kulkarni MS, Friedrik V, Pinto NR. Prevalence of diabetic complications in rural Goa, India. Indian J Community Med. 2011; 36: 283-6.

[24] Jia WP, Shen Q, Bao YQ, Lu JX, Li M, Xiang KS. Evaluation of the four simple methods in the diagnosis of diabeticperipheral neuropathy. Zhonghua Yi Xue Za Zhi. 2006; 86: 2707-10.

[25] De Beradis G, Pellegrini F, Fanciosi M, Belfiglo M, Di Nardo B, Greenfield S, et al. Are Type 2 diabetic patients offered adequate foot care? The role of physician and patient characteristics. J Diabetes Complications 2005; 19: 319-27.

[26] Al-mahroos F and Al-roomi K: Diabetic neuropathy, foot ulceration, peripheral vascular disease and potential risk factors among patients with diabetes in Bahrain: A nationwide primary care diabetes clinic-based study. Annals of Saudi Medicine. 2007; 27 (1): 25-31. 
[27] Karter, Stevens MR, Brown AF, Duru OK, Gregg EW, Gary, Beckles GL, Tseng CW, Marrero DG, Waitzfelder B, Herman WH, Piette JD, Safford and Ettner SL: Educational disparities in health behaviors among patients with diabetes: The Translating Research Into Action for Diabetes (TRIAD) Study. BMC Public Health. 2007; 7: 308.
[28] Shah VN, Kamdar PK and Shah N: Assessing the knowledge, attitudes and practice of type 2 diabetes among patients of Saurashtra region, Gujarat. Int. J. Diabetes. Dev. Ctries. 2009; 29 (3): 118-122. 